\title{
Hacia una educación humanizadora
}

\section{Antonio Pérez Esclarín}

Transformar la educación es un desafío que tenemos desde hace décadas, pero ¿hacia dónde debemos apuntar los cambios a emprender?, es quizá un tema en el que no siempre hay coincidencias. Vamos a conversar en esta oportunidad con el Dr. Antonio Pérez Esclarín: pedagogo, filósofo y escritor nacido en Berdún, España, quien ha vivido gran parte de su vida en Venezuela formando parte del movimiento internacional de Educación Popular Fe y Alegría y como docente investigador de la Universidad Simón Rodríguez. Pérez Esclarín ha recorrido toda la geografía venezolana y gran parte del continente sembrando en el corazón de educadores y educadoras un nuevo modo de entender el acto de educar. Desde su amplia y fecunda experiencia en educación nos comparte sus apreciaciones en relación a la educación que necesitamos y los caminos para avanzar hacia el reto de cambiarla.

\section{S.A.: ¿Hacia dónde deben apuntar los cambios en educación?}

Hacia la humanización. Se trata de volver a la educación no solo de conocimientos sino también de sentimientos y valores, debemos apuntar a formar el corazón, razón y espíritu. Se trata de retomar ese sentido integral que no todos entienden, es decir, no sólo educar a todos sino de educar a toda la persona, la educación trata de construir la persona. En general los centros educativos se concentran en instruir, no ayudan al crecimiento del ser y convivir, muchas veces lo empobrecen porque, entre otras cosas, promueven la repetición, penalizan la discrepancia, no terminan de entender que tan importante como aprender matemáticas es aprender a convivir con los demás. En un mundo con graves problemas de inclusión, discriminación y violencia necesitamos que los centros educativos asuman la tarea de humanizar a todos y todas.

\section{S.A.: ¿No sería esta una tarea muy amplia para la escuela?}

También se trata de enfatizar el papel de la familia, ella es la principal escuela y debe recuperar su papel de formadora, su rol no se reduce a inscribir a los hijos en un centro educativo pues la familia es raíz de 
identidad, forma en unos valores o antivalores, tiene una historia, forma en actitudes y valores a partir del propio ejemplo. Si en casa somos agresivos y violentos, nuestros hijos aprenderán a serlo también. La familia es la primera unidad social, allí compartimos distintas personas, distintos géneros, distintas generaciones y relaciones, por eso allí está el germen de la convivencia, la semilla para aprender a valorar a los otros y otras, es un espacio para aprender a valorar las diferencias. En general, la sociedad debe educar en su más amplio sentido, en esto las instituciones tienen también un rol formativo.

\section{S.A.: ¿Esto que planteas sobre lo que es educar lo ves implícito en los currículos oficiales?}

Normalmente en los preámbulos de todas las leyes y documentos normativos de la educación existe un lenguaje humanista, se propone una educación para la persona; pero cuando se concreta el currículo en el aula se traduce en una instrumentación para formar profesionales. A veces dudo si los que hacen el currículo entienden lo que es ser educador. Hay aprendizajes que no están presentes en los currículos; tenemos centros que entienden, por ejemplo, que es importante trabajar la inteligencia espiritual y logran tener espacios para la meditación, meditar no es reflexionar, sino silenciarse; necesitamos aprender a hacernos preguntas, eso es lo que nos hace humanos, el árbol vive, el perro vive, pero viven sin preguntas... Es necesario estructurar estos y otros aprendizajes e integrarlos en el currículo. La calidad en educación es materia pendiente, se limita a realizar pruebas estandarizadas para medir conocimiento, aunque los mismos que las promueven proclaman la educación humanizadora. De los pilares de la educación que planteó el informe Dellors, a la hora de la verdad no son tomados en cuenta el aprender a ser y el aprender a convivir, son saludos a la bandera porque la acción educativa se orienta a la formación del entendimiento, al hacer, al desarrollo de competencias para ser profesionales exitosos, pero a lo mejor, esos mismos profesionales tienen serias debilidades en la vivencia de valores humanos... ojala las universidades puedan dar el título de persona junto al de abogado, médico... porque muchos están raspados como personas: prepotentes, engreídos, incapaces de mantener unas relaciones humanas dignas, porque repito la educación sigue atrapada en el elemento instruir, nos olvidamos de lo que nos ha dicho Coleman que para triunfar en la vida el coeficiente emocional es más importante 
que el coeficiente intelectual. La educación en el mundo ha fracasado en su objetivo fundamental que es hacer mejores personas. El desarrollo tecno-científico no se está traduciendo en desarrollo humano, por ello hay que volver al sentido de la mayéutica, el sentido kantiano, lo planteaba también Montesory... que educar no es desarrollar conocimientos, sino que es prender una llama, enseñar a vivir. Necesitamos volver a los grandes pedagogos y educadores: Sócrates, con sus preguntas, Freinet, Montesory, Freire... Es necesario recuperar la esencia de la Educación Popular, su esencia es humanizadora, busca formar sujetos más humanos para poder construir un mundo más humano, no olvidemos que en Educación Popular tenemos un pilar político, no politiquero, de transformación del mundo para hacerlo más humano.

\section{S.A.: ¿Cómo ves el papel de los directivos para avanzar hacia esta educación humanizadora?}

El papel del directivo es fundamental, debe formar equipo y he allí la base de su liderazgo, debe poner la escuela en movimiento, tratar de que la escuela se vaya estructurando como lugar o centro de humanización, su papel es de motivar, de comprender a sus docentes...debe ser experto en humanidad y pedagogía, no puede ser una persona que se refugia en los papeles, metido en su oficina, debe ser una persona que está pendiente, son líderes que generan equipo. Siempre sueño con el directora o directora que recibe a los niños y niñas en la entrada, que atiende con cercanía a los representantes y comunidad, y por esa manera de relacionarse lo perciben como modelo de humanidad. Es necesario repensar lo burocrático, el directivo no puede usar el poder para su beneficio, para imponer su perspectiva, quienes detentan poder lo deben utilizar para hacer crecer a las personas, pensemos en Jesús de Nazaret como modelo de maestro, él siempre uso su poder para ayudar a los demás, en definitiva para servir.

\section{S.A.: ¿Y los educadores o educadoras? ¿Están ellos y ellas atrapados también en un enfoque de instrucción?}

Los educadores están cansados de llenar papeles, es demasiada la burocracia de los sistemas educativos y de los currículos...la educación ha entrado en un proceso de no saber que significa educar, muchos planificadores del sistema educativo no son educadores, y muchas veces 
abortan procesos en lugar de ayudar a que se generen, las planificaciones deberían ser un impulso para lograr cambios, pero más bien se convierte en un peso, tenemos que repensarla, la planificación es necesaria, pero a veces nos llenamos de formatos y el objetivo es cumplir con ellos, mientras el espíritu innovador se pierde, así como el entusiasmo.

Para el futuro de la humanidad los educadores somos muchos más importantes que los economistas, los ingenieros o los militares. Al educador hay que tratarlo de acuerdo a la trascendencia de su misión: nosotros somos los que construimos el corazón de la patria. Nosotros somos arquitectos de personas, creamos el capital más importante que son las personas. En contextos donde el educador (a) es maltratado(a), siempre cito una reunión de hace unos meses en Alemania donde un grupo de ingenieros, abogados, psicólogos, médicos... se dirigieron Angela Merkel señalando que debía equipararse sus sueldos a los educadores, y ella les decía que eso no es posible, porque "cómo se va a pagar igual a ustedes que a las personas que les hicieron ser lo que son ustedes". Nosotros formamos a todos los demás, la principal lotería que le puede tocar a un grupo de niños(as) es tener un buen maestro o profesor, nosotros podemos marcar personas para el bien y para el mal. Tener un maestro flojo, sin ilusión, podría ser un problema; en definitiva todos nosotros recordamos a profesores que fueron importantes en nuestra vida, y no los recordamos porque nos instruyeron, no los recordamos porque por fin aprendimos a sumar fracciones o porque aprendimos inglés... los recordamos porque nos sentimos valorados y respetados, porque en un momentos de dificultad esa persona nos tendió la mano, sentimos que realmente nos comprendía... esa es en definitiva la esencia de volver a una educación humanizadora.

\section{S.A.: ¿Cómo hacemos para pasar de ese docente desmotivado, can- sado de la educación cuya vocación está resquebrajada... a un do- cente humanizador?}

Hay dos cosas fundamentales: en primer lugar, la educación inicial debe cambiar. Las universidades enseñan a "dar clases" a ser profesionales, pero no enseñan a entender la educación. Lo segundo es la formación permanente, es decir vivir en un proceso de formación continua, esa es una riqueza. Suelo decir que entrar a Fe y Alegría es como montarse en un autobús de formación, pues mientras estés allí vas a estar cultivando 
tu mente, tu espiritualidad, porque desde la comprensión de lo que somos podremos ayudar a nuestros estudiantes a ser y hacer. El docente que ha dejado de aprender se convierte en un freno para el aprendizaje de los demás.

La formación no puede entenderse como que ya obtuve un doctorado o maestría... como decía Simón Rodríguez: si terminó su formación solo significa que obtuvo los recursos o medios para seguir aprendiendo. Formarse es un proceso inacabado de hacernos personas, lo peor es sentirnos acabados, que ya no tenemos nada que buscar o aprender, porque habrá siempre una posibilidad de crecimiento, una posibilidad de seguir mejorando. El gran problema es que la gente no vive, la gente es vivida por los demás, no sabemos vivir con pasión. En la Universidad Católica de Venezuela, en una conferencia me hicieron una pregunta sobre si yo creía en la vida después de la muerte. Yo le contesté que eso a mí no me preocupa, lo que me preocupa es si había vida antes de la muerte, pues la mayor parte de la gente nace, crece, se casa, se profesionaliza... y se muere sin saber para qué ha vivido. El aprendizaje es esa pregunta fundamental: ¿para qué vivo yo?, ¿cuáles son mis metas, mis ideales? La gente tiene biología, pero no tiene biografía, no es autora de su propia vida. Por eso, para mí tenemos que cambiar ese modelo que tenemos tan introyectado sobre lo que significa la formación entendida como capacitación para obtener titulación, a este modelo de ayudar a descubrir las potencialidades de cada uno.

\section{S.A.: Esto requiere también de una transformación del sentido de vida...}

Creo que hay una necesidad en el ser humano de transcender y crecer en espiritualidad porque ella es el sostén de la vida. Yo he trabajado mucho sobre la inteligencia espiritual, hay un temor de la gente a entrar en sí misma, hay un mundo interior que tenemos por conquistar, la gente tiene miedo del silencio, por ello nos hemos creado tanto ruido y tanta prisa, tenemos que recuperar la cultura del silencio y la meditación, recuperar la oración, el sentido profundo del mundo interior, como decía San Agustín "No corras, que a donde tienes que llegar es a tu propio corazón"; encuéntrate contigo mismo, vuelve al silencio, deja la charlatanería. Porque en el silencio podrás escuchar la voz de tu corazón que es la voz de Dios, porque el silencio no es ausencia de palabra, 
está lleno de vivencia, es centrar la atención en algo importante. Los niños y jóvenes están acostumbrados a ver el silencio como castigo, "Cállense" solemos decirles como regaño, pero el silencio es la matriz de la palabra verdadera, necesitamos callar tanta palabrería hueca, tanta mentira... Solo si entramos en el silencio podemos reorientarnos como personas, necesitamos entrar en él no para quedarnos allí sino para salir al encuentro positivo con el otro y con la naturaleza. Todo eso es reto en una intención de transformación de los currículos educativos. Hacia allá tenemos que caminar. 